\title{
The General Plan of St. Petersburg 2005 - 2025: prerequisites, ideas, implementation
}

\author{
Andrei Vaitens ${ }^{1, *}$, Victor Volkov ${ }^{1}$, Sergey Mityagin ${ }^{1}$ \\ ${ }^{1}$ Saint Petersburg State University of Architecture and Civil Engineering, Saint Petersburg, Russia
}

\begin{abstract}
Nowadays, the main urban planning document of St. Petersburg - the General Plan 2005 - 2025 is in the process of updating and revising a number of positions. In this regard, it seems important to consider the reasons for the proposed changes, as well as the stages of its development, its main ideas and periods of its implementation from 2005 to 2015. Also, environmental impact is considered.
\end{abstract}

\section{Introduction}

The prerequisites for the development of this urban planning document were the changes in the socio-political and economic life of Russia after 1991, the controversial period of the development of the country and St. Petersburg in the 1990s, and the completion of the deadline for the implementation of the previous city-regulating document - the General Plan for the Development of Leningrad and the Leningrad region 1987 - 2005, which determined the direction of the joint development of the city and the region, which had an agglomerative character [1] (Fig.1).

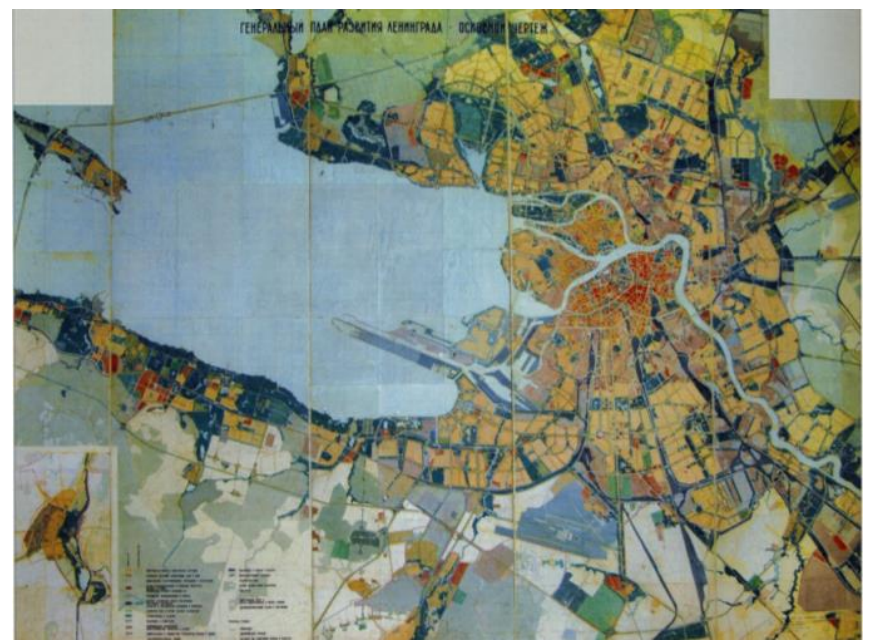

Fig. 1. The General Plan for the Development of Leningrad and the Leningrad region 1987 - 2005.

* Corresponding author: spbgrado@s,spbgasu.ru 


\section{Methods}

The General Plan and the Building Rules of Leningrad (1989) were in force throughout the 1990 s, but due to a radical change in the economic conditions of land use since 1992, only a few city-planning projects have been developed taking into account these documents.

There were two opposite directions in the urban development of St. Petersburg at the end of the 1990s - the preservation of the trend of extensive urban development that existed in the 20th century with a consistent expansion of the developed territories, or the turn to the strategy of intensive reconstruction of previously developed territories within the stabilized boundaries of built-up areas and city boundaries.

In developing the existing General Plan in 2000-2004, a second trend prevailed. The idea of developing the city from the city borders to the center was adopted.

In 2003 - 2004, the Concept of the General Plan was developed, which defined the following strategic development goals of St. Petersburg [2]:

- development of St. Petersburg as a center of science, education, tourism, services, and modern production;

- increasing the efficiency of using the city's territories,

- development of the historical center of St. Petersburg;

- development of its polycentric structure with the further formation of urban centers in peripheral areas;

- development of the urban transport system;

- development of the communication and transport framework of St. Petersburg;

- transformation of a historically established industrial heartland with the removal of a number of particularly harmful enterprises;

- increasing the investment attractiveness of certain parts of the city.

Not all of these goals were fully implemented later.

In 2004, this Concept was approved at the city level and the development of the City General Plan itself began. Zoning schemes for the city's territories, schemes for the development of engineering and transport infrastructure, as well as borders and protection zones for historical and cultural monuments were developed. Economic documents - urban plans for socio-economic development were largely declarative in nature and were only partially implemented later.

As part of the General Plan, stages of its implementation with current goals were identified:

- first stage - 2005 - 2010 - the period of implementation of the priority tasks for the implementation of this document;

- second stage - estimated period - 2010 - 2015 - the period for which all the main design decisions of the General Plan were calculated;

- forecast period - 2015 - 2025, during which it was supposed to determine the main areas of the urban development strategy of St. Petersburg.

In 2004 - 2005, the General Plan passed all the approvals in the Government of the city and the procedure of public hearings in all 18 administrative districts of St. Petersburg. In December 2005, after numerous approvals, the General Plan for the Development of St. Petersburg was approved by a special city law "On the General Plan of St. Petersburg and the boundaries of the zones of protection of cultural heritage on the territory of St. Petersburg" [3]. 


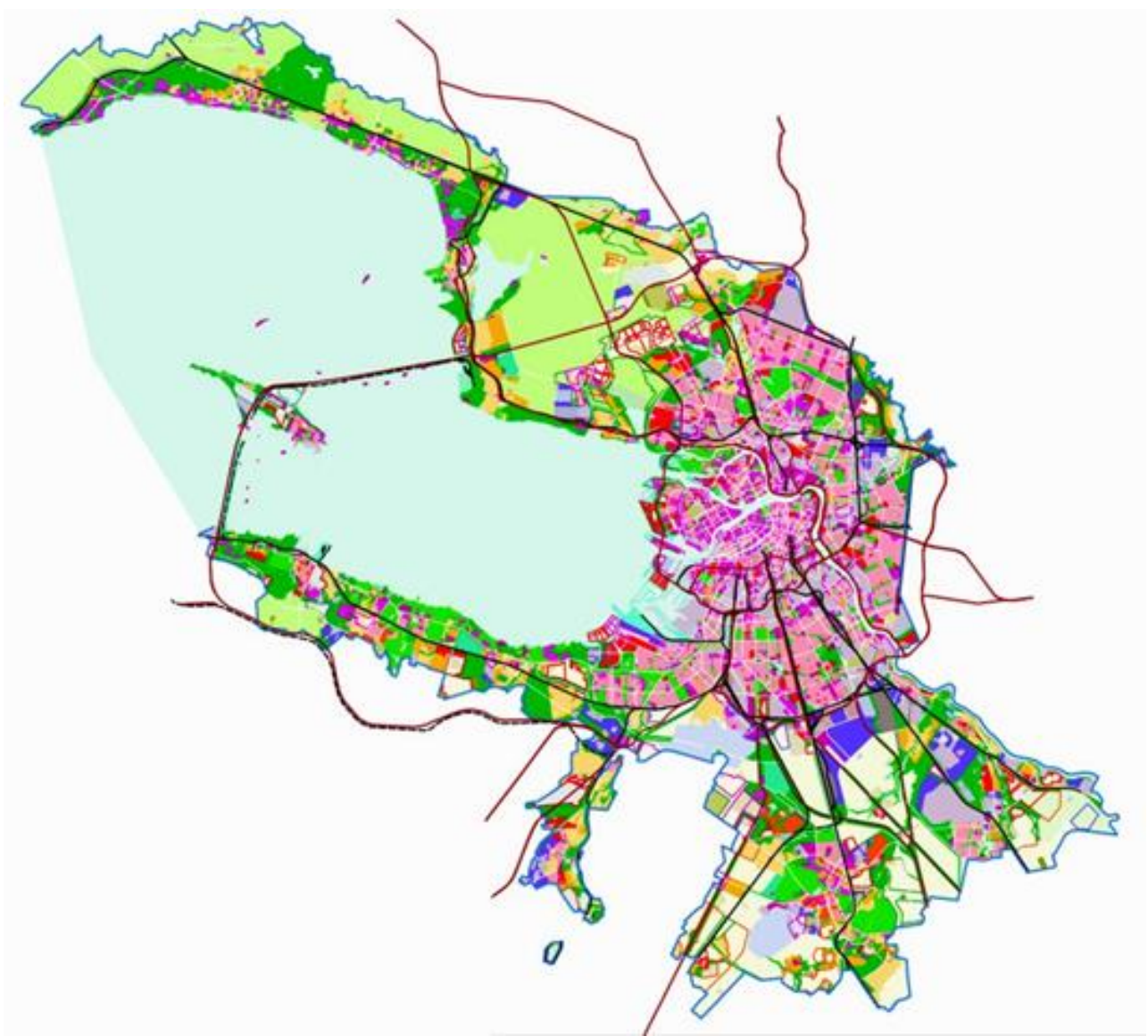

Fig. 2. The General Plan of St. Petersburg $2005-2025$.

\section{Results}

By the beginning of the development of the General Plan, the City Planning Code of the Russian Federation had been in force for more than a year, but its practical use came up against the inconsistency of its norms. In particular, it was difficult to combine the functional and territorial zones in the development of general plans and rules for land use and development of populated areas [5]. The rules of land use and development of St. Petersburg as a document of urban zoning and as an instrument for the implementation of the future General Plan were developed in parallel with it. Urban zoning in these rules was noted in the following documents [5]:

1) the procedure for applying and amending the Rules for Land Use and Development;

2) map of urban zoning;

3) city planning regulations.

Thus, the Rules for Land Use and Development established the boundaries of territorial zones (residential, social and business, industrial and others) and the regulations for construction transformations in these zones. 
By the beginning of the 2010s, such measures as the completion of the Ring Road, protective dam structures, partial construction of the Western High Speed Diameter, the development of the subway network were carried out. In 2018, sports facilities were built for the World Cup (Fig. 3). However, a number of economic indicators for the implementation of the General Plan of St. Petersburg in 2005, in particular providing housing for the population, was not achieved [2].

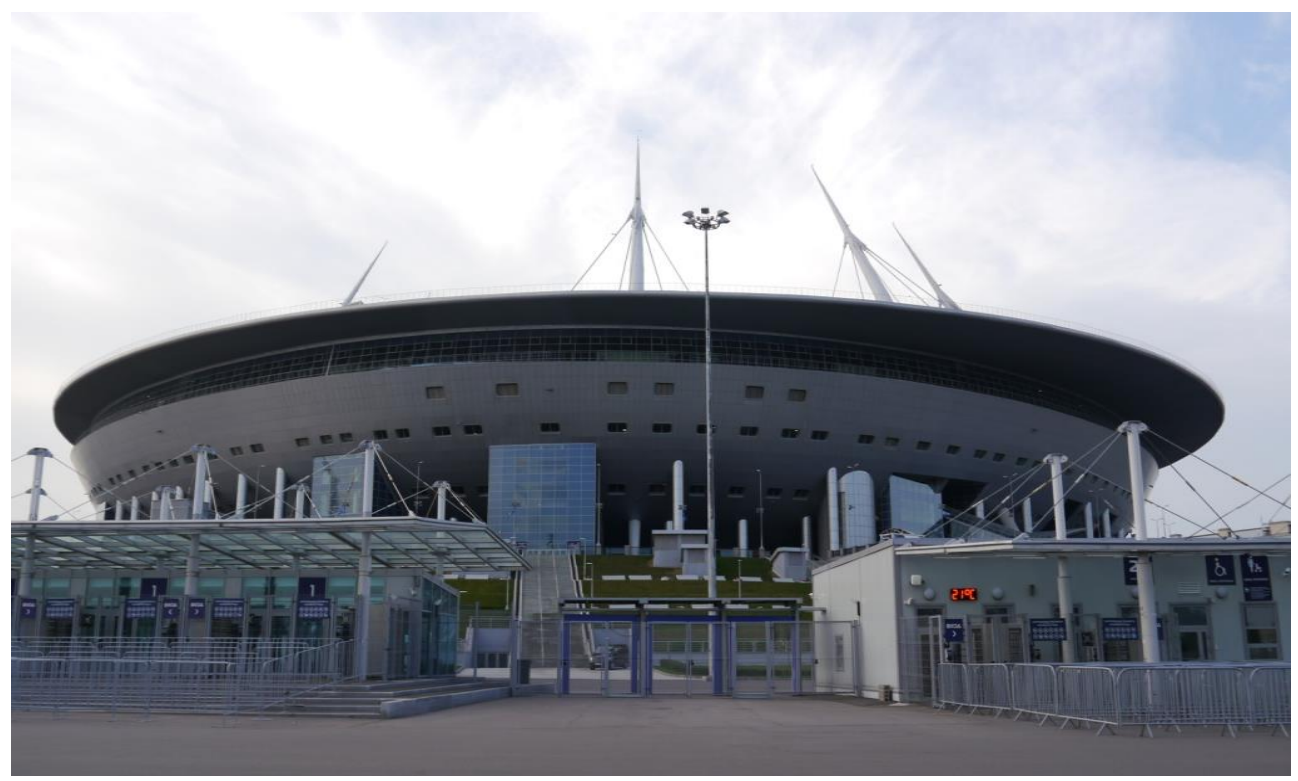

Fig. 3. Gazprom Arena sports complex.

\section{Discussion}

Problems of urban development interaction between two neighboring subjects of the Russian Federation - St. Petersburg and the Leningrad region existed both in the 1990s and later. For the business community and the population, the city and the region have long been regarded as a single territory for mutual activity. The enterprises and institutions located in St. Petersburg provide jobs and services in many social spheres for many residents of the Leningrad region. There are constant contacts and joint interests of the population of St. Petersburg and the Leningrad region. According to expert estimates, about 400 thousand residents of the Leningrad region work on a regular basis in St. Petersburg, and about 700 thousand residents of St. Petersburg in the summertime live in gardening establishments and settlements of the Leningrad region [4]. The red color in Figure 4 shows the zones of active influence of St. Petersburg on the neighboring territories of the Leningrad region.

Under the natural territorial restrictions (Gulf of Finland) of St. Petersburg, it will be necessary to transfer a number of functions that are already difficult to be fully realized by the city to the territory of the Leningrad Region. These include production, logistics, transport and trading functions. At the same time, garbage disposal is often a controversial topic between the city and the region. 


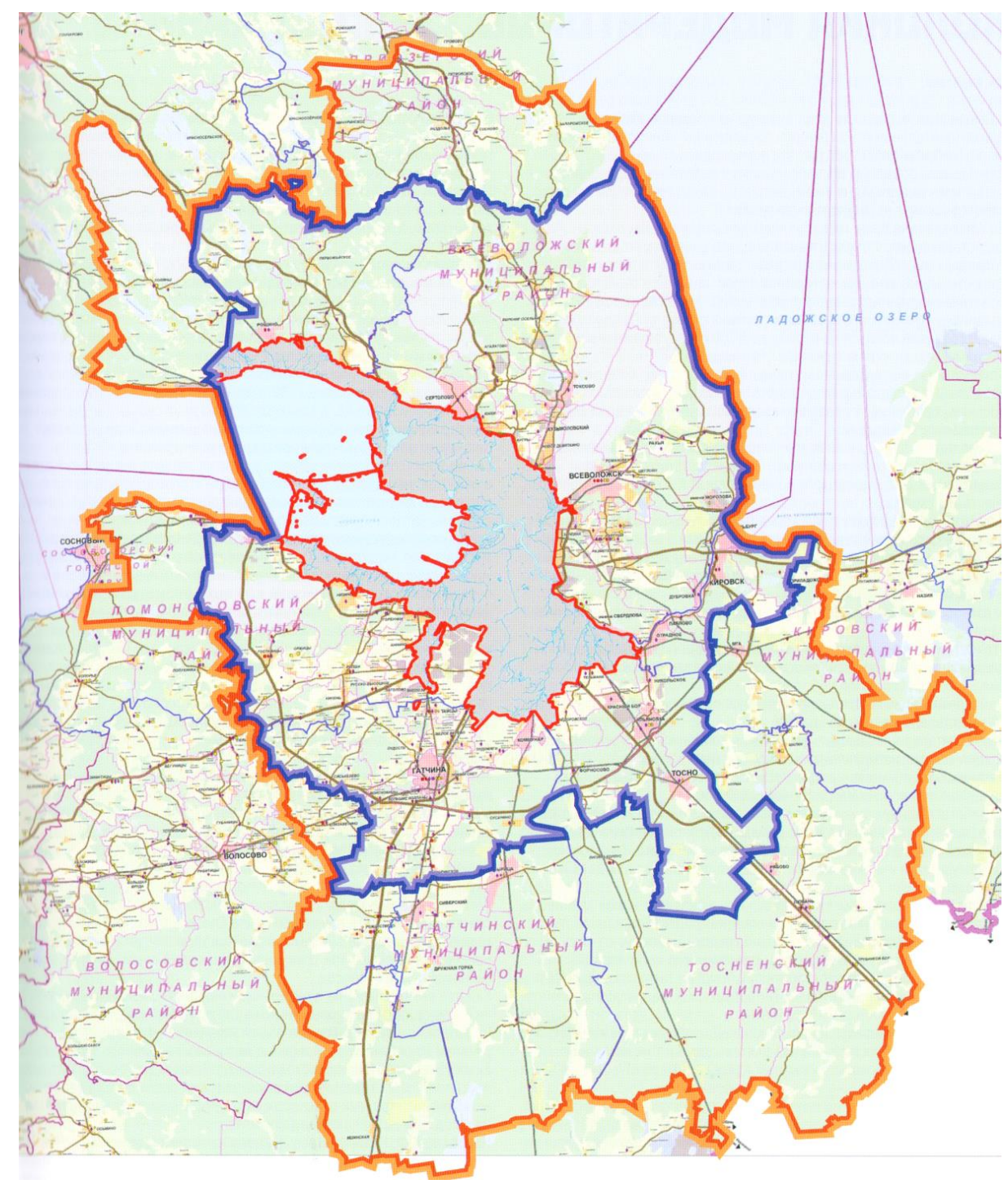

Fig. 4. The boundaries of the active urbanization of St. Petersburg and the zone of active influence of the city on the territory of the Leningrad region.

To solve the problems and conditions of joint development, already in the 1990s it became clear that there is a need to create a joint agglomeration development plan for St. Petersburg and the Leningrad region. These works were started in 2002 - 2005 in the process of preparing the General Plan of St. Petersburg. During this period, work was done to determine the borders, to form and develop the Suburban zone of St. Petersburg, including the territory belonging to the Leningrad region (Fig. 5). 


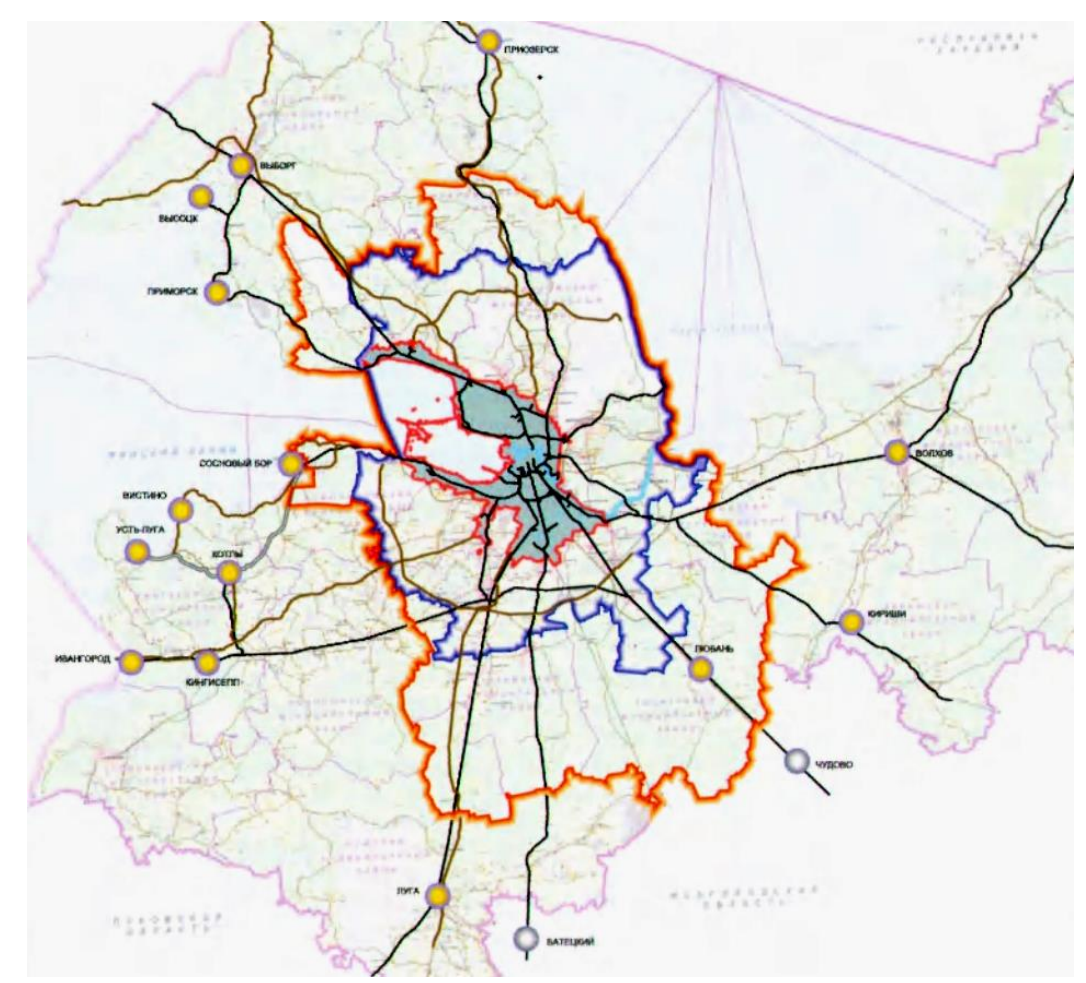

Fig. 5. Problems of determining the boundaries of the agglomeration St. Petersburg - Leningrad region.

To clarify the boundaries of the future agglomeration, the materials of the General Plan of Leningrad of 1966, Leningrad and the Leningrad region of 1987 were used. Work to clarify various aspects of the development of the agglomeration of St. Petersburg Leningrad region continued after the approval of the General Plan of the city $2005-2025$. At the same time, it was assumed that the agglomeration border passes through the final points of mass migration, corresponding to approximately 1.5 hour transport access from the city center. [4].

\section{Conclusion}

The search for a solution to the city-region agglomeration problems led to the updating of the General Plan for the Development of St. Petersburg with the revision and correction of a number of its provisions, which began in 2015 and continues up to the present moment.

In 2016 - 2017, work began on the preparation of a Concept for joint urban development of St. Petersburg and the Leningrad region for the period up to 2030 with a prospect up to 2050 [4]. The provisions of this Concept will be taken into account when developing the General Plan of St. Petersburg for the period from 2018 to 2028 with a prospect until 2048 and making amendments to the existing Territorial Planning Scheme of the Leningrad region. Thus, the implementation of the General Plan for the Development of St. Petersburg will embark on a course of searching for the formation of an agglomeration of two federal subjects of Russia - St. Petersburg and the Leningrad region, determining its borders and mutual interests. 


\section{References}

1. A.G. Vaitens, Proceedings of the IX Creative Forum "Architectural Seasons" at SPbGASU: collection of proceeding of scientific and practical conference, SPbGASU, 21-23 (2019)

2. S.A. Ershova, General plans of St. Petersburg. 1703-2013, p. 500, Piter.ru., St. Petersburg (2014)

3. The law of St. Petersburg "On the General Plan of St. Petersburg and the boundaries of the zones of protection of cultural heritage on the territory of St. Petersburg" dated December (2005)

4. A.R. Batchaev, Architectural Petersburg, No. 6 (49), 8 - 11 (2017)

5. S.D. Mityagin, Bulletin of civil engineers, №2 (7), 6-9 (2006)

6. S.D. Mityagin, In the collection "Economic problems in architecture, urban planning and investment and construction activities. Current state and challenges" Materials of the All-Russian Scientific and Practical Conference of the faculty, young scientists of St. Petersburg State University of Architecture and Civil Engineering, 44 - 48 (2019)

7. S.D. Mityagin, Materials of the IV scientific and technical conference, $346-347$ (2019)

3. L. Albrechts, P. Healey, K. R. Kunzmann, Journal of the American Planning Association, 69(2), 113-129 (2003) doi:10.1080/01944360308976301

4. L. Bertolini, Planning Practice and Research, 14(2), 199-210 (1999) doi:10.1080/02697459915724

5. Y.P. Cai, G.H. Huang, Z.F. Yang, Q. Tan, Applied Energy, 86(4), 480-495 (2009) doi:10.1016/j.apenergy.2008.09.025

6. C.T., Cunningham, H. Quan, et al., BMC Medical Research Methodology, 15(1) (2015) doi:10.1186/s12874-015-0016-Z

7. A. Perova, Architecture and Engineering, 1(1), 4-8 (2016)

8. S. Greenfield, E.C. Nelson, et al., JAMA: The Journal of the American Medical Association, 267(12), 1624-1630 (1992) doi:10.1001/jama.1992.03480120062034

9. T.V. Hartert, H.H. Windom, et al., American Journal of Medicine, 100(4), 386-394 (1996) doi:10.1016/S0002-9343(97)89513-7

10. L. Lavrov, F. Perov, Architecture and Engineering, 4(1), 4-10 (2019) 